\title{
Research on the development of sports dance events in Hainan Province
}

\author{
XiaohongGuo,ShuhongZhang,DongdongChen \\ Haikou college of economics, Haikou570203, China \\ Meilixinshijie_3@163.com
}

\begin{abstract}
Since China's reform and opening up, not only focus on the development of social economy, especially for the construction of spiritual civilization. As an important part of the construction of spiritual civilization, sports dance competition plays a very important role in the construction of spiritual civilization. This paper analyzed and explored the development of China's sports dance competitions, and focuses on the development of key tourist city of Hainan province of China's sports dance competition, hoping to provide effective advice to Hainan Province's sports dance competition work smoothly.

Keywords Hainan province sports dance competition development research
\end{abstract}

Sports and dance belong to two separate projects, and sports dance is the effective integration of sports and art sports. After years of development, China's current sports dance has shown ornamental characteristics and artistry, attracted all the people's eyes, gained widespread attention, especially in Hainan province in which the sports dance competition is notable. But throughout the development of China's sports dance project, it is not difficult to find, in order to promote the development of sports dance in China, organized sports dance events provide no small help for it, especially in China, the State Sports General Administration will introduce the concept of competitive sports to the sports dance project, the sports dance events become the national sport project, which greatly boosted the development of sports dance in china. As a result, the importance of sports dance events in the development of sports dance projects in China is becoming increasingly important. Therefore, in order to further promote the development of sports dance competitions in China, this paper analyzes the development of sports 
dance events, hoping to put forward helpful suggestions to promote their better and faster development.

\section{1 .The development of sports dance competition in China \\ 1.1 external power}

At present, there are some points about the external motive force of the development of sports dance events in China. The first point is defined by the socialist market economic environment of our country. After the reform and opening, China has carried out a series of economic reforms, from the original plan of economic reform in the public ownership as the main body, a variety of private ownership economy model of economic development, in this case, China's market environment can be established, and in the ensuing development process to the gradually perfect. In such a socialist market economy environment, China's sports culture market has also been the development of space. Coupled with the improvement of people's living standard, material economy rich people for physical health requirements have been raising awareness, people are more willing to participate in sports dance competitions in, it also provides a good environment for the development of China's sports events. The second point is in recent years, with the development of China's economy, the improvement of international status, our country more and more attention to the development of sports, national attention on sports dance competition will not only further improve the sports concept applied to the sports dance competitions, sports dance will also belong to the sports competition project. Especially in recent years, it has organized a large number of sports dance events, which provide an effective guarantee for the prosperity and development of sports dance events in china.[1]

\section{2 internal power}

First of all, with the improvement of people's living standard, people pay more and more attention to the construction of spiritual civilization, but also pay more and more attention to their own health. And to participate in sports dance sports can cultivate people's mood, strengthen the people's physical exercise, so the social masses for sports dance competition enthusiasm, interest are greatly improved, which provides intrinsic motivation for Chinese sports dance competition development. Secondly, due to the influence of the market environment, sports dance training institutions are rapidly increasing, which has provided a good internal environment for the development of sports events in china. Finally, the governments of various countries and regions actively organize various sports events, which provide a good way for the development of China's sports events.

\section{The development of sports dance events in China}

Open the history page, to study the development process of China's sports dance competition, will be the development of China's sports dance competition consists of three stages. The first stage is the initial stage of the sports dance competition. We investigate, analyze and study the relevant literature and the existing data. At present, from the academic point of view, the initial stage of the development of sports dance competition in China is defined as 1991 - 1999. We are such a division reason in 1991 May China Dance Sport Association officially registered, and after this year the establishment of China held the first national 
sports dance championship. After that, we have a nationwide sports dance championship every year. Until 1999, China took nine times. However, in this period, there are no other sports dance competitions except the sports dance championships. Therefore, it can be said that during this period, the development of sports dance competition in our country is still relatively simple, so it can be summarized as the preliminary stage. The second stage is the comprehensive stage of the development of sports dance events in china. In 2000, China's sports administration in order to promote the development of dance competitions, issued a series of sports dance documents, these documents carried out a detailed plan for China's sports dance competition, and to develop methods and measures, which are to provide protection for the development of China's sports dance competition. At the same time this year in China under the support of the government, in addition to the national sports dance competition held outside the normal, also organized a national DanceSport Championships, National Youth Sports Dance Championships, the National City sports dance competitions and other events, in this period, China's sports dance competition showing a thriving, diversified development potential. Therefore, we can conclude that there is a comprehensive development stage. The third stage is the reform stage of sports dance competition. From 2008, China's sports dance competition has entered the stage of reform. The reason why we call it the reform phase is that since 2008, China has a variety of sports dance competitions held more frequently, a variety of sports dance sports also showed the characteristics of popularization and maturity. Therefore, in order to avoid all kinds of sports dance competition is too frequent, appear heavy, but also in order to increase the quality of China's sports dance competition, China's sports dance competition for a series of reforms. Therefore, we can be explained as the reform stage.[2]

\section{The development of sports dance competition in Hainan Province}

Hainan, as an economically developed and popular tourist city. Naturally, the development of its sports dance competition is also very focused. In recent years, Hainan has organized a large number of sports dance events.

3.1the specific reasons for the prosperity and development of sports events in Hainan:

\subsection{1 government support}

Hainan municipal government in order to respond positively to the call of the state, Construction of spiritual civilization in Hainan, held a lot of sports dance competition. Hainan's first sports dance competition is the Hainan provincial Party Committee Propaganda Department, Hainan Provincial Federation of Hainan Province, jointly organized by the association of dancers. The dance competition hopes that $\mathrm{i}$ can put the concept of competitive sports into the competition, and in order to promote the development of sports dance in Hainan province. And it is exactly because of the support of the government of Hainan, so that the activities of the sports dance activities carried out smoothly.

\subsection{2 the positive response of the people of Hainan}

Hainan province is the only tropical island province in our country, its tourism industry is very developed, not only by domestic people like and respected, in the 
international visibility is relatively high. More and more tourists from home and abroad are welcome. The development of tourism in Hainan has promoted the development of Hainan's economy and improved people's living standard. When people's material life is satisfied, people pay greater attention to spiritual needs. In this environment, Hainan people are more interested in sports dance events. First of all, this activity is positive, to meet the needs of people's spirit. Hainan people are willing to spend more time to carry out this activity. Secondly, to take part in sports competitions can exercise people's bodies, so that people better exercise.

\subsection{3 large-scale increase in sports dance institutions}

In this strong domestic fitness atmosphere, in Hainan, sports dance institutions also showed a large-scale growth trend. In addition to any personal business of sports dance organization, after approved by the competent department of Haikou style administration, also became the tears of Haikou City Sports Dance Association, which is the only one of the non-profit social organizations. In this group, a collection of international standard dance, ballroom dance, square dance, aerobics and other forms of sports to dance. The purpose of this association is according to the specific requirements of the sports work in our country's sports policy in Hainan province and Hainan, the majority of sports dance lovers together, dance game for the promotion of language popularization of sports dance cultural exchanges. At the same time, she also participated in some international large-scale sports dance events and communication activities, in order to improve the standard of sports in dance, and then promote the development of Hainan national sports dance fitness activities.[3]

\section{2sports dance events held in Hainan}

\subsubsection{Hainan Sports Dance Championship}

By the end of 2016, the Hainan National Fitness Sports Dance Championship has been through ten years. The tournament has grown up to be an annual event in Hainan. In 2015, the National Fitness Sports Dance Championship at the end of the Golden Hall of Hannan International Conference and exhibition center. There are twenty-nine teams and nearly 700 clubs taking part in the event. In this sports dance event, respectively, for the open and championship. The 2016 National Fitness Sports Dance Championships in Haikou, the opening ceremony took place in Century Square, Haikou. Hainan provincial leaders took part in the opening ceremony. The sports dance championship this session in order to better implement the State Council's "National Fitness Program", so that the majority of the people of Hainan to participate in physical fitness activities, make people more physical and mental health, and ultimately achieve fitness, build China dream goal. In this sports dance competition, mainly includes forty-five projects, these projects are on the brink of the real life of the people, which allows more viewers to participate in the sports dance competition. Sports dance competition organized by the Hainan Provincial People's government, the provincial sports hall, the Provincial Federation of sports.

\subsection{2 "spring light" Cup sports dance competition}

Hainan's "spring light cup" was held in Haikou in 2015. It is Haikou's first sports dance championships, held in Haikou City stadium, mainly from Hongkong and 
Hainan local 39 teams held. The dance sport event known as the International Dance Festival, sports and dance act of fusion. In the game, with the music of the high pitched passion, full of pathos, players will dance interpretation of rich and colorful, dazzling.[4]

\section{China's Hainan province sports dance development proposal}

At present, although the development of sports events in Hainan province is more prosperous, the people of Hainan are warmly welcomed, but with the development of the times, sports events in Hainan must be reformed and innovative. This paper puts forward some suggestions on the development of sports dance events in Hainan Province:

\section{1 intensify the reform of the evaluation system of sports dance events in} Hainan

In recent years, Hainan has held a lot of large-scale sports events, but in the process of its sports events in the evaluation of a lot of problems. Therefore, it is necessary in order to reform the evaluation system of sports dance events. First of all, to set up a unified game, which is conducive to ensure that the rules of the sports dance competition more clearly. Secondly, the rules of the sports dance competition must be planned, and let the scoring standards quantified, in order to promote the integrity of China's sports dance competition system.

4.2 the development of sports dance event resources, to create Hainan sports dance events

In order to increase the overall level of the sports dance competition held in Hainan Province, we must pay attention to the development of sports dance events. First of all, it can improve the market environment of the development of sports dance events in Hainan Province, and provide a strong guarantee for the advance. Secondly, in Hainan Province, but also the whole of the sports dance competitions focus on packaging and training, can even develop a high-profile sports dance star, and its value will be fully played out, in order to improve the sports dance event's influence. Finally, Hainan province to create a sports dance competition in line with the characteristics of the development of Hainan, and promote its progress.

\section{References}

[1]Watanabe N M,Sources of Direct Demand: An Examination of Demand for the Ultimate Fighting Championship. International Journal of Sport Finance, 2 10(1),pp:26-41,2015.

[2]Giampiccoli A, Lee S W, Nauright J,Destination South Africa: comparing global sports mega-events and recurring localized sports events in South Africa for tourism and economic development. Current Issues in Tourism, 18(3),pp:229 $-248,2015$.

[3]Horne J,Assessing the sociology of sport: on sports mega-events and capitalist modernity. International Review for the Sociology of Sport, 50(4-5),pp:466471,2015. 
[4]Cornwell T B, Sponsorship in marketing : effective communication through sports, arts, and events. Journal of Sport Management, 8(1),pp:127-128,2015. 